DOE/ER/60931-3

\section{MOLECULAR UNDERSTANDING OF MUTAGENICITY USING POTENTIAL ENERGY METHODS}

Progress Report.

for Period January 1, 1990 - June 30, 1992
DOE/ER/60931--3

DE93 006464

Suse Broyde and Robert Shapiro

New York University

New York, New York 10003

\author{
July 1992 \\ Prepared for
}

THE U. S. DEPARTMENT OF ENERGY

AGREEMENT NO. DE-FG02-91ER60931

NOTICE

This report was prepared as an account of work sponsored by the United States Government. Neither the United States nor the Department of Energy, nor any of their employees, nor any of their contractors, subcontractors, or their employees, makes any warranty, express or implied, or assumes any legal liability or responsibility for the accuracy, completeness or usefulness of any information, apparatus, product or process disclosed or represents that its use would not infringe privately-owned rights. 


\section{PROGRE88 REPORT}

\section{A. Project overview}

The objective of our work, for many years, has been to elucidate on a molecular level, at atomic resolution, the structures of DNAs modified by highly mutagenic aromatic amines and hydrocarbons. We have given particular attention to the carcinogens 2-aminofluorene (AF) (Ia, figure 1 ) and its $N$-acetyl derivative, 2acetylaminofluorene (AAF) (Ib, figure 1). Activated forms of both compounds bind to DNA, and the most prominent adducts are those that arise from substitution at position 8 of guanine (IIa and $b$, Figure 1). The mutagenic specificity of these compounds has been explored by a number of groups. As controls, we have also studied their less mutagenic chemically related analogs, and unmodified DNAs. The ultimate purpose of this undertaking is to obtain an understanding of the relationship between DNA structure and mutagenicity.

The underlying hypothesis is that DNA replicates with reduced fidelity when its normal right-handed B-structure is altered, and one result is a higher mutation rate. This change in structure may occur normally at a low incidence, for example by the formation of hairpin loops in appropriate sequences, but it may be enhanced greatly after covalent modification by a mutagenic substance. Other mechanisms may also lead to mutation after covalent modification, for example the operation of induced error-prone repair pathways. Ultimately it is DNA structure, mediated by replication and repair enzymes, that determines whether a mutation will take place.

The methods that we use to elucidate structures are computational, but we keep in close contact with experimental developments, and have been able to incorporate the first data from NMR studies in our calculations. The reason why computational approaches to structure generation are so important in this area is that $x$-ray and spectroscopic studies have not succeeded in producing atomic resolution views of mutagen and carcinogen-oligonucleotide adducts. The NMR method cannot alone yield molecular views, though it has recently done so in combination with our computations. The specific methods that we employ are minimized potential energy calculations using the torsion angle space molecular mechanics program DUPLEX (developed and written by Dr. Brian E. Hingerty) to yield static views. Molecular dynamics simulations, with full solvent and salt, of the important static structures are carried out with the program AMBER; this yields mobile views in a medium that mimics the natural aqueous environment of the cell as well as can be done with current available computing resources.

In order to obtain the most reliable structures possible, we are continuously working to advance the state-of-the-art on the computational front. Many of our efforts involve new methods for dealing with the multiple-minima problem; this impediment prevents the unambiguous identification of the global minimum energy conformation, or even of all important local energy minima. DUPLEX was developed to reduce the number of conformational variables that must be minimized at the same time in comparison to the larger number ( $3 n-6$, where $n=$ the number of atoms) used in cartesian space 
molecular mechanics. We vary only the torsion angles in our program, and hold bond lengths, bond angles, and out-of plane-movements of aromatic moieties fixed. The number of flelible variables in a deoxydinucleoside monophosphate (building block of a DNA helix) is thus reduced to just 12 , including the termini and sugar puckers (Figure 1). We feel that very little is sacrificed by this strategy in determining the structure of modified DNA, as torsion angles changes are very large, in comparison to those of the other variables, while great advantage is derived in optimization capability.

We have also been developing new strategies for searching conformation space and building DNA duplexes from favored subunit structures. We are thus able to compute structures de novo by conformational searches. Included among these techniques is a novel approach for locating and ranking in order of energy structures with unusual hydrogen bonding patterns or denaturation at specified sites. Neither model building, with its attendant bias by the modelers aesthetics, nor experimental input is required in our approach. If, however, high resolution NMR data is available in the form of interproton distances, then these distances can be incorporated as constraints in first stage minimizations, to aid us in locating a structure that agrees with experiment. These constraints are released in the terminal minimizations, to produce unconstrained energyminimized structures that are consistent with the NMR data.

In addition, we are collaborating with a colleague, Dr. Tamar schlick. (Chemistry Department and Courant Institute of Mathematics, New York University), with the goal of interfacing her powerful new algorithms for potential energy minimization and molecular dynamics simulation with DUPLEX. Details of this methodological approach are given in the publication by schlick, et al. (1990).

B. Variation of the structure of $A F-$ and $A A F-m o d i f i e d ~ D N A$ with Bequence. (Theoretical studies With No Experimental Input).

\section{Studies on Unmodified DNA:}

In a pilot project, we implemented a build up technique for polynucleotides akin to one devised for prediction of polypeptide structure from the amino acid building blocks by scheraga and coworkers (for a review of the polypeptide work, see Gibson and Scheraga, 1988). This technique could not be applied to polynucleotides until the advent of supercomputers because the deoxydinucleoside monophosphate building blocks of DNA (Figure 1) have many more torsional angles that must be optimized simultaneously than do amino acids. Briefly, we made large conformational searches for the "dimer" deoxydinucleoside building blocks $d(C p G)$ and $d(G p C)$, and then combined these minima to produce energy minimized structures for the single strand trimer: $d(C p G p c)$. These structures were then employed to search for minimum energy conformations of the duplex $d(C p G P C) \cdot d(G p C p G)$. At each stage, large numbers of trials were necessary because of the combinatorial nature of the searches. It is of interest that the two lowest energy forms of the trimer duplex were. $B$ and $Z$ DNA helices, which agreed with the experimental preferences of the alternating $G-C$ sequence. 
These two computed duplex trimers, built to the energyminimized dodecamer level, yielded full length $B$ and $z$ helixes. Thus, these structures were obtained with no experimental input other than the force field parameters. In addition, many novel double-stranded structures of higher energy were located in the duplex trimers. As our knowledge of genome structure and function grows, some of them may prove to play a role in particular circumstances. A full account of this work has been published (Hingerty, et al., 1989).

\section{Studies on Modified DNA:}

a. AF- and AAF-modified single-stranded DNA; We have also used our buildup techniques to study AF- and AAF-modified oligomers, following a strategy similar to that employed for unmodified DNA. The problem is much more difficult here due to the added flexibility at the amine-base linkage (Figure 1). Yet intensive conformational studies, involving thousands of trials, have been completed. An abbreviated form of this study has been presented at the 1992 meeting of the American Association for Cancer Research : Miao, Y.-S., Hingerty, B.E., Broyde, S. and Shapiro, R., "Mutagenes is by 2Aminofluorene ( $A F$ ) and 2-Acetylaminofluorene (AAF): Implications from DNA Single-strand Conformations", Proc. Amer. Assn. Cancer Res. 33 , 142 (1992). A full-length manuscript is being prepared for publication.

In this work we studied the effects of AF- and AAF-modification at C-8 of guanine in deoxydinucleoside monophosphates (dimers) of all possible sequences. Further, modified alternating CGC trimers were buift up from the CG and GC dimers, and the pentamers GCGAF CG and GCG AAF CG were constructed from the trimers by embedding the trimers in B-DNA. The number of trials run was the following: For dimers, 4,897 trials for all cases except for the AF- and AAF-modified CG and GC sequences. These cases were selected for a pilot test with 31,104 additional trials run for each. In general, the larger search did not prove worthwhile. The new minima found to $5.5 \mathrm{kcal} / \mathrm{mol}$ by the extended search in no case included a global minimum, and (with one exception) contributed in total less than $1.5 \%$ to the conformation population.

The exception came up in the case of $\mathrm{CpG}^{\mathrm{AAF}}$, in which the long search produced the second most stable minimum, $0.76 \mathrm{kcal} / \mathrm{mol}$ above the global one, contributing $6 \%$ of the total $\mathrm{mix}$. It was of the predominant syn-guanine, AAF-base stacking type, but contained syncytosine as well. A number of structures of higher energy with syncytosine were also located by the longer searches, but missed by the shorter ones. This occured because the longer searches included a syn starting conformation for cytosine but the shorter ones did not. It may be worthwhile to include syn pyrimidines in future searches, but apart from this, it may be concluded that the expansion of trials in the long search did not produce results worth the expenditure of computer time.

For trimers, 59,568 trials were run for AF-modification, and 87,572 for AAF-modification. Full details of the methods are provided 
in the Ph.D. thesis of Y.-S. Miao, New York University, 1992, and are to be published.

Conformation of Dimers: $d-G A F_{p N}$ AND $d-G A A F p N(N=A, G, C, T)$ : The global minima and most of the low energy structures for all eight of the 5'-modified dimers studied fall into a single conformational class. Guanine is syn, and stacks at an angle with its $3^{\prime}$-neighboring base, while AF or AAF has close contacts with the bottom or side of the neighboring sugar. The plane of the guanine ring is close to perpendicular with that of the amide bond, and the fluorene ring plane is also at a sharp angle with that of the amide bond. This circumstance creates a wedge-shaped binding pocket. The 3' nucleotide residue binds within the concave surface of this pocket, and the amine $\mathrm{H}-\mathrm{H}$ or acetyl protrudes from the less-hindered convex side.

Two subclasses can be defined, depending on whether the neighboring base is a pyrimidine or purine. In the former case, the pyrimidine forms a triangle with the sides of the pocket, and stacks with both guanine and, to a lesser extent, fluorene. This is illustrated for the global minimum of dG $\mathrm{d}$. in Figure 2 . If the neighbor is a purine, it interacts only with guanine (see the global minimum of $\mathrm{dG}^{\mathrm{AAF}} \mathrm{pA}$, Figure 3 .

Conformation of Dimers: $d-N p G A A F$ (N $=A, G, C, T)$ : A single class of conformation predominates in this series, representing the global minima and most of the low-energy conformers of all four dimers. The fluorene ring participates in a near parallel-stack with the neighboring base, and guanine contacts the side (and top in some cases) of the 5'-sugar. The backbone is right handed, with, however, uncommon angles for the $C-O$ bonds $\phi^{\prime}$ and $\phi(\beta$ and $\epsilon)$.

The modified guanine is syn in these conformers, but some variation can be seen in the glycosyl-bond orientation of the neighbor, with both syn and anti-conformers prominent. The global minimum for CpGAAF (Figure 4) has anti-cytosine, which stacks with the middle and distal fluorene rings (the stack is the same for the anti copformers of $A$ and $G$ ). The global minima for ApG $A A F$ (Figure 5) and GPGAAF have the unmodified purine syn, and it stacks with the middle and proximal fluorene rings (the stack is the same for the syn conformer of C). TpGAAF is an exception to this pattern. The global minimum $T$-anti conformer (no syn-T was observed) stacks with the proximal fluorene ring).

Conformation of Dimers: ${ }^{N N p G} A F \quad(N=A, G, C, T)$ : The dimer class in which the $3^{\prime}-$ residue is modified by aminofluorene shows the most diverse behavior. It is the only group in which the identity of the neighboring base has a profound effect on the nature of the most stable structure(s). Two major subgroups can be defined: one has near parallel base-fluorene stacking, with guanine in a low syn $\left(-20^{\circ}\right)$ glycosyl orientation. the other has guanine anti, with base-base stacking that varies remarkably from one conformer to another.

The global minimum for dTpG AF (Figure 6) illustrates the basefluorene stacking subgroup. The backbone is left-handed (z-type), and guanine stacks loosely on the phosphate. This kind of structure occurs for neighboring $C, A$, and $G$ as well, but occurs $0.6-1.0$ $\mathrm{kcal} / \mathrm{mol}$ above the minimum. The right handed base-fluorene stacked 
conformer that dominated the NpGAAF series can be found here as well, but falls $2.2-3.7 \mathrm{kcal} / \mathrm{mol}$ above the global minimum, in the four dimers.

The guanine-anti, base-base stacked subgroup is diyerse on its own, with the global minima for dCpGAF, dApGAF and dGpG AF showing different features. The minimum for $\mathrm{dCpG}^{\mathrm{AF}}$ (Figure 7 ) has a righthanded backbone, but with gauche $\phi^{\prime}(\epsilon)$ and trans $\psi(\gamma)$ values. The base-base stack has only partial overlap, and is at an angle of about $25^{\circ}$. while the fluorene stacks on the top of the 5'-sugar and on phosphate.

The dApGAF co-global minimum (Figure 8 ) has a B-DNA backbone, but with $\omega(\alpha)$ at $215^{\circ}$ (trans), and the glycosyl angle of both bases near $165^{\circ}$. The fluorene ring stacks on the backside of the $5^{\prime}$-sugar and on phosphate. The bases have a near-parallel stack. However each uses the opposite face to that used in B-DNA for the stack. In terms of their hydrogen-bonding sites, they have essentially changed places. Further, the glycosyl bond of one purine is rotated $60^{\circ}$ with respect to the other so that the amino group of $A$ is over $N-1$ of $G$. If this should occur in single- or double-stranded DNA, it could possibly lead to a mutagenic two-base inversion, or a transition.

The $d G p G^{A F}$ global minimum is illustrated in Figure 9. It displays a right-handed backbone, but with angles of $84^{\circ}$ and $170^{\circ}$ for $\phi$ and $\psi$ ( $\beta$ and $\gamma$ ), and a glycosyl angle of $155^{\circ}$ for the modified $G$. The base-base stack is parallel, with one six-membered ring over the other, while fluorene stacks on phosphate. The orientation of the bases with respect to one-another is novel, however, with the carbonyl group of one $G$ over the amine of the other (and vice-versa) in reverse watson-Crick alignment. If this structure were feasible in larger fragments of DNA, its potential for mutagenic miscoding could possibly be significant.

\section{Summary of Dimer studies: Comparison with Experiment:}

(1) Fluorene-Base Stacking vs. Base-Base stacking: In earlier literature, these were often considered as two mutually exclusive and competing options. In fact, in the low energy minima, both guanine and fluorene generally find stacking partners; one selects the neighboring base, the other the neighboring sugar or phosphate. Fluorene-base stacking is commonly near parallel, while base-base stacking will sometimes be at an angle greater than $20^{\circ}$. In such cases, greater stabilization may result from optimizing the fluorenesugar contacts than by achieving a good base-base interaction.

(2) AAF Conformations VS. AF Conformations: The principal effect of the acetyl group appears to be the destabilization of anti conformations of guanine, and to a lesser extent, conformations on the borderline of syn and anti. In the 5'-substituted dimers, the most stable AF-modified conformations involved syn guanine, and quite similar ones were favored in the AAF series. In the $3^{\prime}$-substituted dimers, the most stable conformations involve anti or low syn guanine. Such structures are disfavored in the AAF series, and the most stable conformations have syn guanine. In the AF series, syn guanine structures are of higher energy. 
(3) 5'-substitution vs. 3'-substitution: one conformational type predominates in the low energy structures for the 5'-substituted adducts of both AAF and AF: right handed, with syn-guanine, imperfect base-base stacking, and fluorene to $3^{\prime}$-sugar contacts.. The AAFsubstituted 3'-adducts primarily displayed good base-fluorene stacking, with syn-guanine in contact with the 5'-sugar. The AFsubstituted $3^{\prime}$-adducts were more diverse, showing a variety of righthanded iow energy structures with guanine anti, good to poor basebase stacking and fluorene to 5'-sugar contacts. Substituted 3'adducts primarily displayed good base-fluorene stacking, with syn guanine in contact with the 5'-sugar. The AF-substituted $3^{\prime}$-adducts were more diverse, showing a variety of right-handed low energy structures with guanine anti, good-to-poor base-base stacking and fluorene to 5\%-sugar and phosphate contacts. The NpGAF series also featured a left-handed, low energyconformation with good basefluorene stacking and guanine-phosphate contacts.

(4) Effect of Neighboring Base, This was important only in the $3^{\prime}-\mathrm{AF}$ substituted series, where $\mathrm{TPG} A \mathrm{~F}$ had a left-handed base-fluorene stacked form as global minimum, and the remainder displayed differing right-handed forms with base-base stacking.

(5) Comparison to Experiment. dApG ${ }^{A F}$ and aApG $A A F$ were examined by NMR and CD (Santella, et al. 1980; Leng, et al.. 1980). The authors concluded that fluorene-base stacking was more sjgpificant in the former than the latter. A detailed NMR study of dCpGAAF has been carried out by Evans and Levine (1988), who found strong cytosinefluorine stacking, with guanine syn, and the guanine $C(8)$ to amine $N$ bond $\left(\alpha^{\prime}\right)$ near $90^{\circ}$. Our results agree with these experimental ones, though individual conformers that match the specific sugar pucker and $c-5$, to $c-4$ ' $(\gamma)$ torsional angles suggested by Evans and Levine have not yet emerged in our study.

Trimer conformations: $d C p G A F p c$ and $d C p G A A F p c$ : In the case of the AF-modified trimers, the global minimum (Figure 10) and the majority of low energy trimers fall into a single class. This has a backbone considerably rearranged from that present in a normal $B-D N A$ stack. Near-parallel base-base stacking takes place between cytosines (1) and (3), with the amino of each over the carbonyl of the other. syn guanine has looped out and is in contact with the edges of the two cytosines, and the fluorene ring stacks on the back of the $3^{\prime}$-end sugar and on its phosphate. In this compact structure, the terminal $5^{\prime}-\mathrm{OH}$ and $3^{\prime}-\mathrm{OH}$ have come close to one another, with the 0 to 0 distance measured at $4.82 \mathrm{~A}$. (The normal distance from a 5'-0 to the $3^{\prime}-0$ of the same sugar in $B-D N A$ is about $4.33 \mathrm{~A}^{\circ}$ ). A structure of this type could possibly form a loop in single stranded DNA.

Several other quite different conformations could also be found at relatively low energy. One of them, which involves an anti $i x=$ $170^{\circ}$ ) guanine to cytosine (3) to cytosine (1) stack, with fluurene to sugar (1) contacts, is illustrated in Figure 11. The guanine to cytosine (3) stack shows normal alignment, but the cytosine to cytosine stack is reversed, as described for the global minimum. 
The AAF-modified trimer showed two co-global minima, both of which had the the same general shape and stacking interactions as the major AF-modified class described above. The two co-minima differed from one another in several of their backbone angles, however. One of them is pictured in Figure 12. Most of the other low energy AAFmodified conformers were in that general class. The oH-ends of these structures again were about $4.8 \mathrm{~A}$ from one another, with the potential for forming a loop. One alternative conformer type (energy $1.08 \mathrm{kcal} / \mathrm{mol}$ above the global minimum) is pictured in Figure 13 . It exhibits a syn guanine to cytosine (1) to cytosine (3) stack, with fluorene in contact with the underside of sugar (3). Normal $B$ or $Z$ single-stranded structures, with conventional C-G-C stacking, were not found at energies up to $3.5 \mathrm{kcal} / \mathrm{mol}$ in either the AF or AAFmodified structures.

AF- and AAF-Modified Pentamers. To explore whether the global minima for $C \mathrm{CG}^{A F} \mathrm{PC}$ and $\mathrm{CpG} A \mathrm{PC}$ could be incorporated into larger DNA oligomers, a limited number of trials was run in which dGMP was added to the $3^{\prime}$ and $5^{\prime}$ ends of the AF trimer in Figure 10, and the resulting structure was minimized. The same procedure was followed with the AAF trimer in Figure 12. The most stable pentamer conformers were produced when the added monomer fragments were started in B-DNA geometry They are illustrated for dGPCpGAFpCpG in Figure 14 and for dGPCPG $A F_{\mathrm{pCpG}}$ in Figure 15. The above AF-modified conformer was $3.5 \mathrm{kcal} / \mathrm{mol}$ more stable than the conformer with B-DNA geometry (GAF anti), while the above AAF-modified pentamer was $\mathrm{kF}^{13.7}$ syn). An AAF-modified pentamer in the geometry of Figure 14 was also feasible. Its energy was slightly higher $(1.6 \mathrm{kcal} / \mathrm{mol})$ than the one in Figure 15.

The AF-modified pentamer is noteworthy in that it contains a G1-G5-C2-C4 stack. The C4 end is "capped" by the binding pocket formed by modified $G 3$ and $A F$. G3 contacts the edge of $C 4$ (and to a lesser extent, C2), while the distal ring of AF stacks onto the backside of the C4-sugar. This situation resembles that of the parent trimer. The 5'-O of GI is now $9.36 \mathrm{~A}^{\circ}$ from the $3^{\prime}-0$ of $\mathrm{G5}$. (The distance from $0-^{\prime}$ ' of one residue in $B-D N A$ to $0-3^{\prime}$ of the $3^{\prime}$-neighbor is about $10.5 \mathrm{~A}^{\circ}$ ) and they are oriented in tho same direction. The pentamer thus spans the approximate distanc. used by a dimer in a DNA chain. Further buildup should be possible, but has not yet been attempted.

The AAF-modified pentamer (Figure 15; contains G1-C2-C4 parallel stack. G1 and $C 2$ overlap in a normal watsori-crick manner, while the C2-C4 stack has reverse Watson-Crick geome'cry. As in the AF case above, this stack is capped by the G3-AAF pocket. The proximal AAF ring has a partial overlap (the angles between the pianes is $22^{\circ}$ ) with $\mathrm{C4}_{4}$, while the distal ring contacts the sugar of $\mathrm{C4}$. G5 is out of the stack, in contact with those areas of $G 1$ and $C 2$ thit would Iine the major groove in B-DNA.

Thus, these studies show that modification by AF or AAF perturbs the structure of short single stranded DNA oligomers. Among the novelties observed are sequence inversion, reverse watson-crick stacking arrays, and the formation of compact loops with out-of 
sequence stacking. If such features should persist in larger fragments of single-stranded DNA, they could provide a molecular basis for substitution, base-inversion and deletion mutants.

In an intensive continuation of this work that is now ip progress, we are combining the single stranded trimers dCpG ${ }^{A}$ pc and dCpGAAPC with dGpCpG to generate energy minimized duplexes. The number of trials needed approaches the 100,000 range for these energy minimized duplex trimer searches.

b. AAF-Modified Double-stranded DNA: In this study, minimized potential energy calculations were employed to locate and evaluate energetically a number of different models for DNA modified at carbon-8 of guanine by AAF, using very limited searches. Three different duplex nonamer sequences were investigated. In addition to syn guanine models which have some denaturation and carcinogen-base stacking in certain cases, and a $z-D N A$ model, we have found two new types of structures in which guanine remains syn and the AAF is placed in the minor groove of a B-DNA helix. One type features Hoogsteen base pairing between the modified guanine and a protonated cytosine, with a sharply bent helix. The other (here termed the "wedge" model because the aromatic amine is wedged into the minor groove) can maintain a single hydrogen bond between 06 of the modified guanine and $\mathrm{N} 3$ of protonated cytosine, with much less deformation of the helix, and close Van der Wals contacts between the AAF and the walls of the minor groove. Both types of structure (as well as the related forms produced by deprotonation of cytosine) are energetically important in all three sequences examined. The wedge-type minor groove model, which is most favored except in alternating G-C sequences, had been previously observed in combined NMR and computational characterization of an aminofluorene (AF) modified guanine opposite adenine in a DNA duplex undecamer (described below). This work has been published (Shapiro, et al., 1989).

\section{c. studies on the structures of Modified Double-stranded oligonucleotides, Employing NMR Data.}

1. An AF modified duplex 11-mer with adenine opposite the lesion site: molecular view of a mismatch mutation: A combination of NMR data from the Patel-Grunberger laboratories at columbia University and our calculations have produced the first combined experimental and theoretical structure of a DNA-aromatic amine adduct.

Furthermore, an entirely new type of structure for this adduct was found: The aromatic amine is wedged into the minor groove of a DNA duplex in a manner that minimizes the exposure to solvent of the hydrophobic moiety. Only the edges of the aromatic rings are exposed. This orientation is achieved by positioning the modified guanine in a syn conformation, rotated approximately $180^{\circ}$ in the glycosyl linkage from its normal anti domain. An unusual hydrogen bond from $\mathrm{NH}-1$ of protonated adenine to 0-6 of guanine stabilizes the structure at acidic (but not neutral or basic) pH. Adenine was selected as partner for the modified guanine in the duplex because AF modification often leads to $G C \rightarrow T A$ transversion mutations (see section B3bii of our accompanying grant proposal). One plausible mechanism for these genetic changes would be the formation of $\mathrm{G}^{\mathrm{AF}}$ to $\mathrm{A}$ mispairs during 
replication, as in our duplex. This work has been published (Norman, et al., 1989).

2. AF-modified DNA duplex 11-mers with hypoxanthine, guanine or cytosine opposite the lesion site: As experimental data had suggested that $G$ to $G$ mispairs may also be involved in $A F$ mutagenesis, the Patel-Grunberger group prepared the above modified 11-mer with guanine opposite the AF-modified guanine. The NMR data was difficult to interpret in this case, however, so the analgg with hypoxanthine (which lacks the guanine amino group) opposite GA was prepared as well. It afforded data amenable to interpretation, and this data was of value in interpreting the results from the $G$ to $G$ mismatch. We have computed molecular views of both structures, which agree with the data. They reveal that AF is again situated in the minor groove of B-DNA, in an orientation that is very similar to that found in the $A$ to $G^{A F}$ mismatch (Figure 16). A weak hydrogen bond to 0-6 of the modified guanine from $\mathrm{H}-1$ of hypoxanthine adds stability to the structure. This bond is absent in the GAF to G mispair. A manuscript describing this work is in preparation.

We have also computed, without expiremental input, a molecular view of an analogous structure in a duplex in which a normal $C$ partner is opposite $h$-modified G (Broyde, et al., 1990).

3. An AAF modiried duplex nonamer with deoxycytidine opposite the lesion site: We have solved the structure of an AAF-modified duplex nonamer with the usual Watson-Crick sequence: cytosine opposite the modified guanine. This work was carried out in collaboration with Prof. Thomas Krugh and coworkers at the University of Rochester, who carried out the NMR investigation. We employed Krugh's measured interproton distances to guide our conformational searches with DUPLEX, and followed this with unconstrained molecular dynamics studies with the program AMBER, which includes solvent and salt. A major and minor structure were delineated. In both, the modified guanine is syn, rather than anti, which is normal in B-DNA. The guanine is displaced from its normal base-stacked position and does not hydrogen bond to the opposite cytosine. The major conformer features AAF-base stacking, while the minor one places the AAF in a position in which it protrudes from the minor groove, and lacks stacking interactions with adjacent bases. The DNA is bent in both structures.

A video of the dynamics trajectory (169 picoseconds) of the major conformer is included. The interproton distances during the trajectory are consistent with the NMR data. Thus the view is a realistic one of the solution mobility of this conformer, but the time frame was too short, due to computational limitations, to reveal a transition between the major and minor conformers. The time span required for this change would be orders of magnitude larger than our trajectory. Preliminary accounts of this work have been published (Broyde, et al., 1991;, O'Handley, et al., 1992), and a fully detailed manuscript is in preparation.

An abnormal syn guanine thus appears to be an important feature or the conformation of $A F-$ and AAF-modified DNAs. If it is not repaired by an error-free mechanism in vivo, then it could be 
misinformational at the replication fork, and lead to a mutation. Some of our ideas on mutagenic conformations are presented in Broyde, et al., (1990).

4. The structure of a DNA duplex hexamer cross-linked by mitomycin: Mitomycin is a clinically useful antibiotic and antitumor agent, and a mutagen. This substance can form a monoadduct to the $\mathrm{N}-$ 2 position of guanine or a diadduct to two appropriately positioned guanines on opposite strands. NMR studies by Prof. D. Patel and coworkers (Columbia University) on a di-adduct in a hexamer duplex synthesized by Prof. M. Tomasz and co-workers (Hunter college, City University) produced interproton distances. The data was used in our computations to model the structure.

Two structures were calculated that were compatible with the NMR data and indistinguishable experimentaliy. They differed in the conformation of the saturated ring of mitomycin, and may actually interconvert in solution. In both structures, the mitomycin was situated in a B-DNA duplex with a widened minor groove; the mitomycin resides in closer proximity to one of the two DNA strands. The end base pairs are not hydrogen-bonded. The cross-link is thought to be responsible for the anti-tumor action of mitomycin: presumably it interferes with replication by preventing the unwinding of DNA. Details of this work are given in Norman, et al., (1990).

5. Structures of the trans adducts formed at $\mathrm{N}-2$ of guanine in DNA by $(+)$ and $(-)$ anti-benzo[a]pyrene diol epoxides (BPDE): It has been known for over a decade that $(+)$ anti BPDE is tumorigenic while its (-) anti mirror image is not (Conney, 1982). The trans-ąnti major adduct formed by reaction of the $(+)$ isomer with the $\mathrm{N}^{2}-$ position of guanine is believed to be responsible for the carcinogenicity of the parent compound, while the milror image adduct formed by the (-) reactant appears much less active in that respect (Conney, 1982). Thus, this pair of adducts offers an ideal system to explore structure-function relationships.

We have solved structures for these two adducts. Indeed, we predicted that the structural difference resides in opposite orientations of the pyrenyl moiety in the B-DNA minor groove. The long axis is oriented toward the $5^{\prime}$ end of the modified strand in the $(+)$ adduct, and toward the $3^{\prime}$ end of the modified strand in the (-) adduct (Singh, et al., 1991).

Subsequently, experimental interproton distances for a DNA duplex 11-mer became available from synthetic efforts by Geacintov and co-workers (NYU) and the NMR studies of Patel and his colleagues (Columbia). We employed the data in computational studies to determine the structure of this adduct. The results verified fully our predictions concerning minor groove orientation (Cosman, et al., 1992; de los Santos et al., 1992).

6. Structure of the $\mathrm{cis}$ adduct formed at $\mathrm{N}-2$ of guanine in DNA by $(+)$ anti-benzo[a]pyrene diol epoxide (BPDE): This adduct is a minor product of the tumorigenic BPDE isomer. It is formed by cis, rather than trans, opening of the epoxide ring (see figure 1 in singh, et al., 1991). The structure of a DNA duplex 11-mer 
containing this adduct has now been determined by the same collaboration given above for the BPDE trans-anti adducts. The result, illustrated in Figure 17, places the benzo[a]pyrene moiety in an intercalated position between adjacent base pairs. It displaces the modified guanine from its normal base-stacked position within the helix. and base-pairing by this guanine is ruptured. The guanine retajns a glycosyl conformation within the anti range, but of a value $60^{\circ}$ different from its usual one in B-DNA.

\section{REFERENCES}

Broyde, S., Hingerty, B.E., Shapiro, R. and Norman, D. in Nitroarenes, Howard, P., Ed., Plenum Press, New York, pp 113-123 (1990).

Broyde, S., Hingerty, B.E., Xu, R., O'Handley, S.F. and Krugh, T.R., Proceedings of the First Energy Research Power supercomputer Osers symposium, Gaithersburg, MD, 1991, Natl. Technical Information Service, Springfield, VA.

Conney, A.H., Cancer Res. $\underline{\text { ? }}$. 4075-4917 (1982).

Cosman, M., de los Santos, :. Fiala, R., Hingerty, B.E., Singh, S.B., Ibanez, V., Margulis, L., Live, D., Geacintov, N., Broyde, S. and Patel, D.J., Proc. Natl. Acad. Sci. USA 89, 1914-1918 $(1992)$.

de los Santos, C., Cosman, M., Hingerty, B.E., Ibanez, V., Margulis, L.A., Geacintov, N.E., Broyde, S. and Patel, D.J., Biochemistry 31, 5245-5252 (1992).

Evans, F.E. and Levine, R.A., Biochemistry 27, 3046-3055 (1988).

Gibson, $K$. and Scheraga, $H .$, in structure and Function, Vol.1:

From Proteins to Ribosomes, Sarma, R.H. and Sarma, M.H., Eds.,

Adenine Press, Schenectady, N.Y., pp 67-94 (1988).

Hingerty, B.E., Figueroa, S., Hayden, T. and Broyde S.,

Biopolymers 28, 1195-1222 (1989).

Leng, M., Ptak, M. and Rio, P., Biochem. Biophys. Res. Commun. 96, 1095-1102 (1980).

Norman, D., Abuaf, P., Hingerty, B.E., Live, D., Grunberger, D., Broyde, S. and Patel, D.J., Biochemistry 28, 7462-7476 (1989).

Norman, D., Live, D., Sastry, G., Lipman, R., Hingerty, B.E., Tomasz, M., Broyde, S. and Patel, D.J., Biochemistry 29, 2861-2875 (1990).

O'Handley, S.F., Sanford, D.G., Xu, R., Lester, C., Hingerty, B.E., Broyde, S. and Krugh, T.R. in structure and Function, Vol. I, Nucleic Acids, Adenine Press, Schenectady, N.Y., pp 137-146 (1992). Santella, R.M., Kriek, E. and Grunberger, D., Carcinogenesis 1 , 897-902 (1980).

Schlick, T., Hingerty, B.E., Peskin, C.S., overton, M.L. and Broyde, S. in Theoretical Biochemistry and Molecular Biophysics, Beveridge, D.L. and Lavery, R., Eds., Adenine Press, Guilderland, N.Y., pp 39-57 (1990).

Shapiro, R., Hingerty, B.E. and Broyde, S., J. Biomol. Struct. and Dynam. I, 493-513 (1989).

Singh, S.B., Hingerty, B.E., Singh, U.C., Greenberg, J.P., Geacintov, N.E. and Broyde, S., Cancer Res. 51, 3482-3492 (1991). 
A.

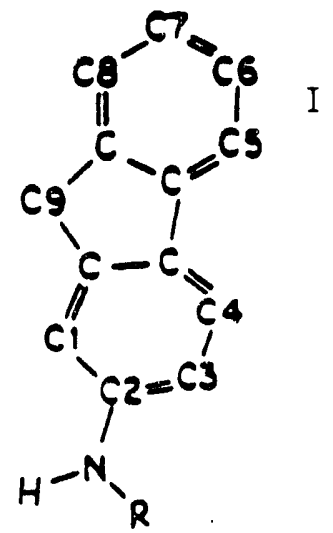

Ia: $\mathrm{R}=\mathrm{H}$

Ib: $\mathrm{R}=\mathrm{OSCH}_{3}$

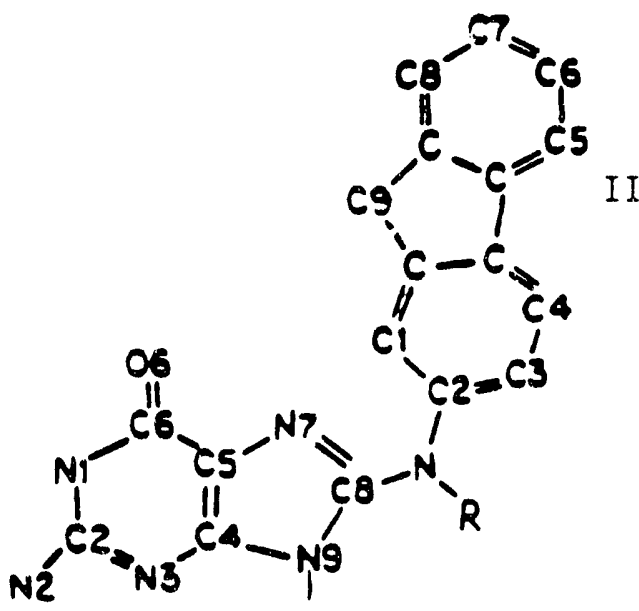

Iia: $\mathrm{R}=\mathrm{H}$

IIb: $\mathrm{R}=\mathrm{COCH}_{3}$

B.

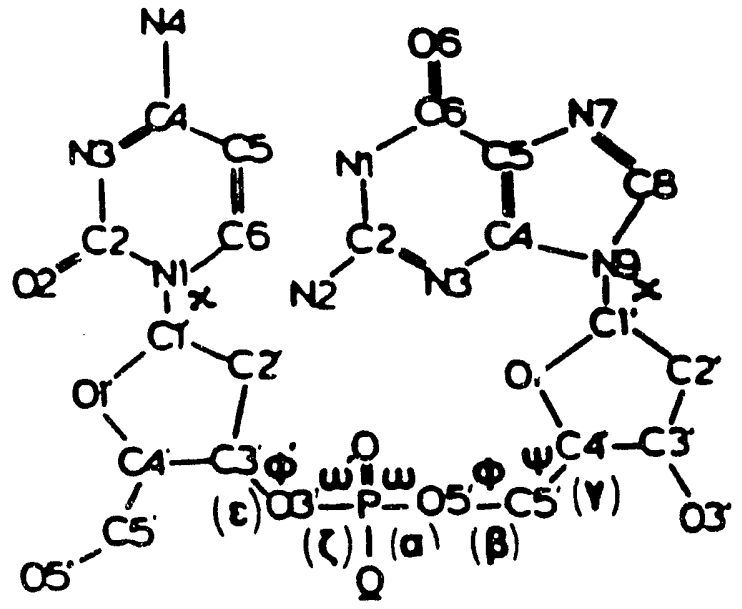

Structure, numbering scheme, and variable conformational angle designations for $\mathrm{d}(\mathrm{CPG})$. The dihedral angles A-B-C-D are defined as follows: $x, \mathrm{Ol}^{\prime}-\mathrm{Cl}^{\prime}-\mathrm{N} 1-\mathrm{C}$ (pyr); $\mathrm{Ol}^{\prime}-\mathrm{Cl}^{\prime}-\mathrm{N} 9$ -

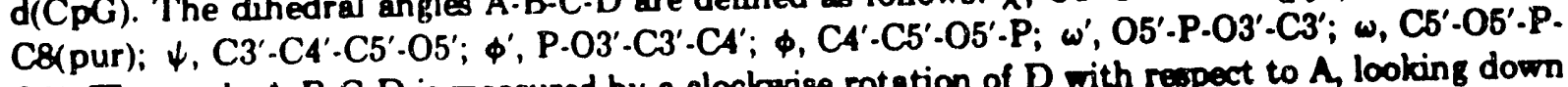
O3'. The angle A-B.C.D is messured by a clockwise rotation of D with respect to $A$, looking down the B-C bond. A eclipsing D is $0^{\circ}$. Sugar pucker in the calculations is defined by the peendorotation parameter $\mathbf{P}$. An additional flexible torsion angle, Me, employed for the thymine methyl is defined as C6-C5-C-H. IUPAC torsion angle deaignations are given in parentheses. In the IUPAC convention $180^{\circ}$ is adde 

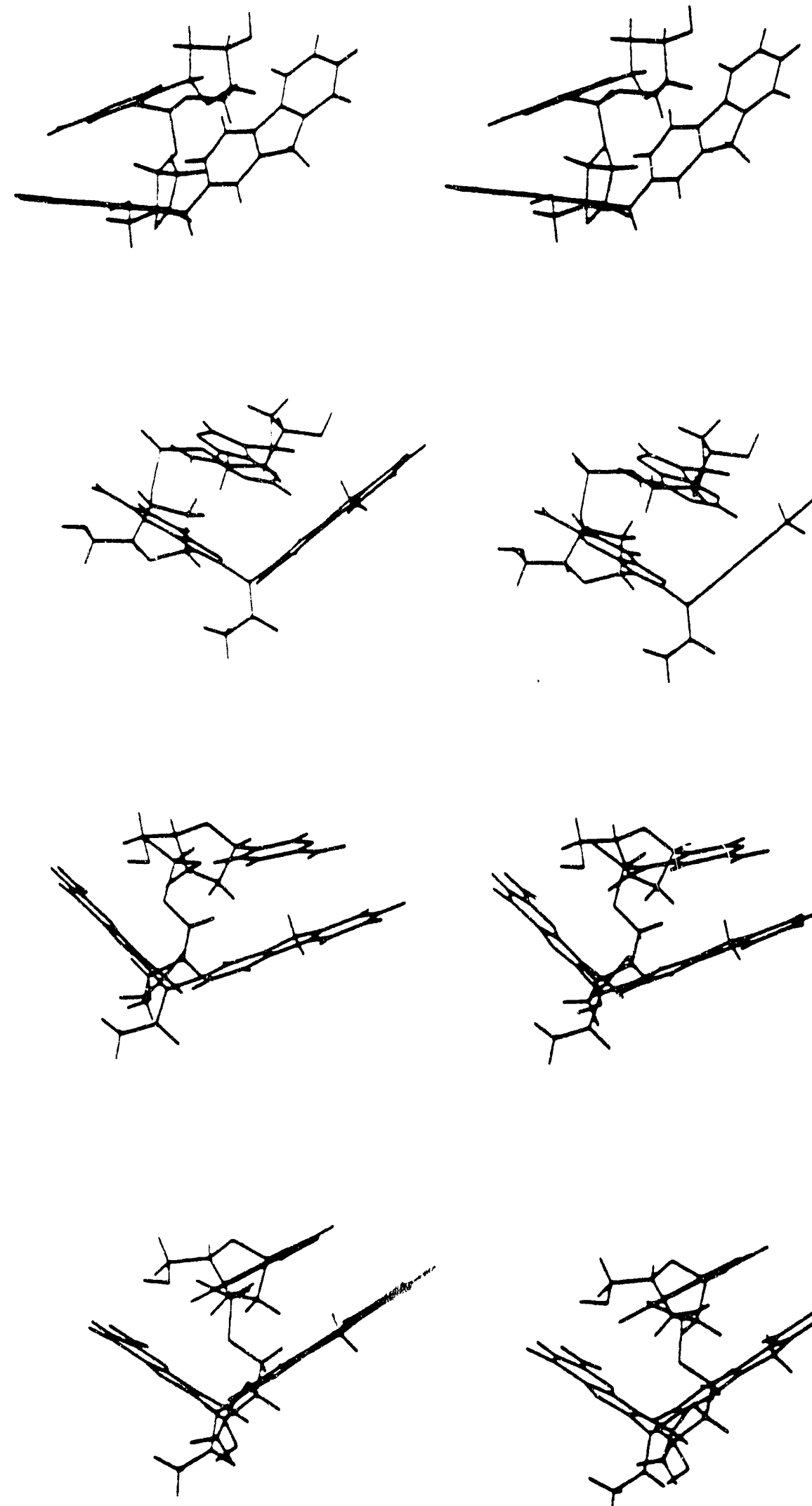
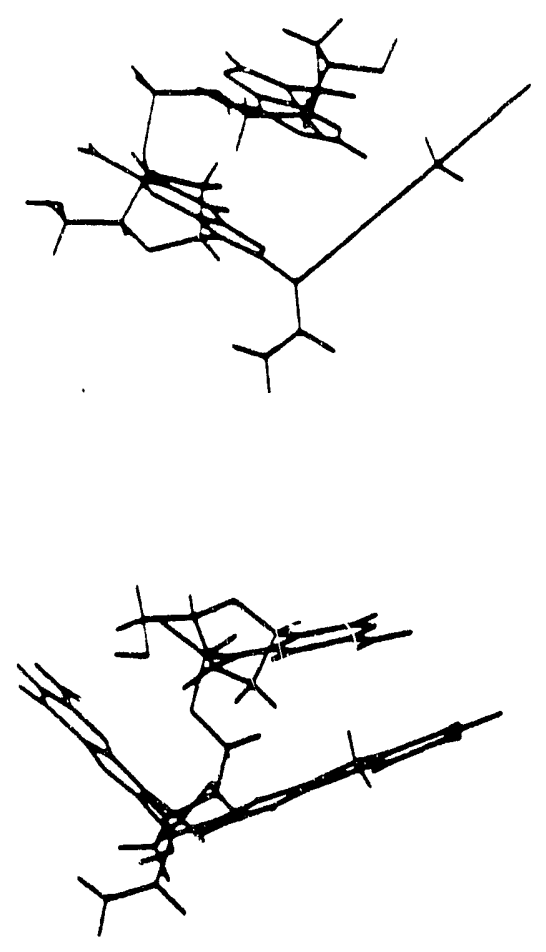

Figure 4.

$d(C) G-A-A F)$
Figure 3.

$d(G-A \cdot A F-p \cdot A)$

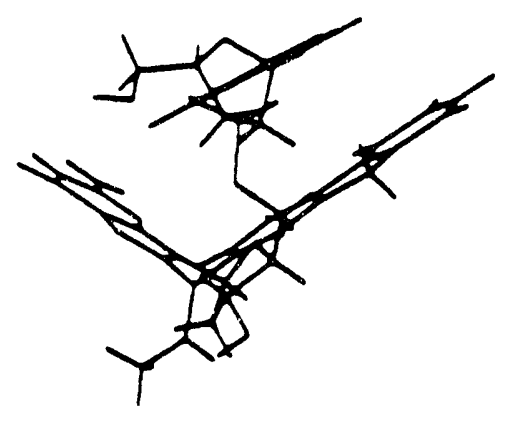

Finure 5.

$d(A)(-A \cdot F)$ 

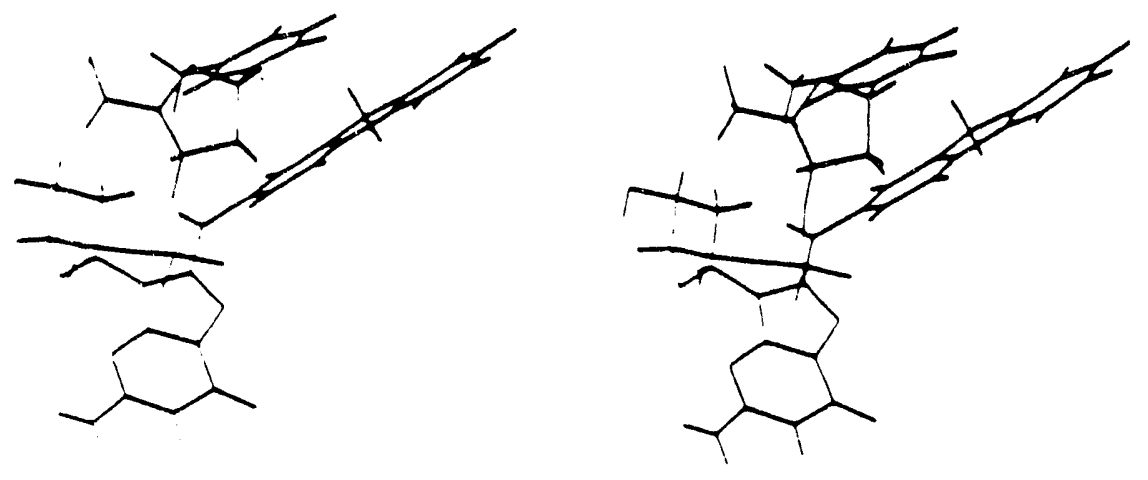

Figure 6. $d(T p G-A F)$
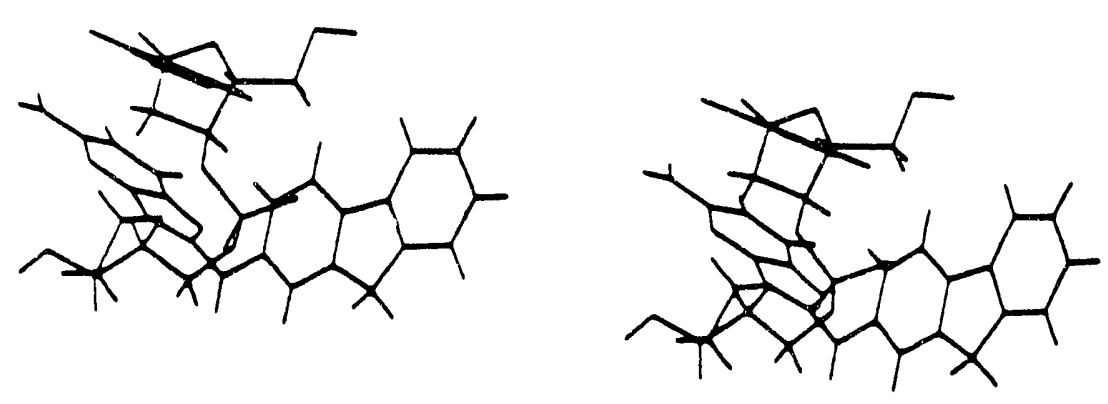

Figure 7.

d (CDG-AF)
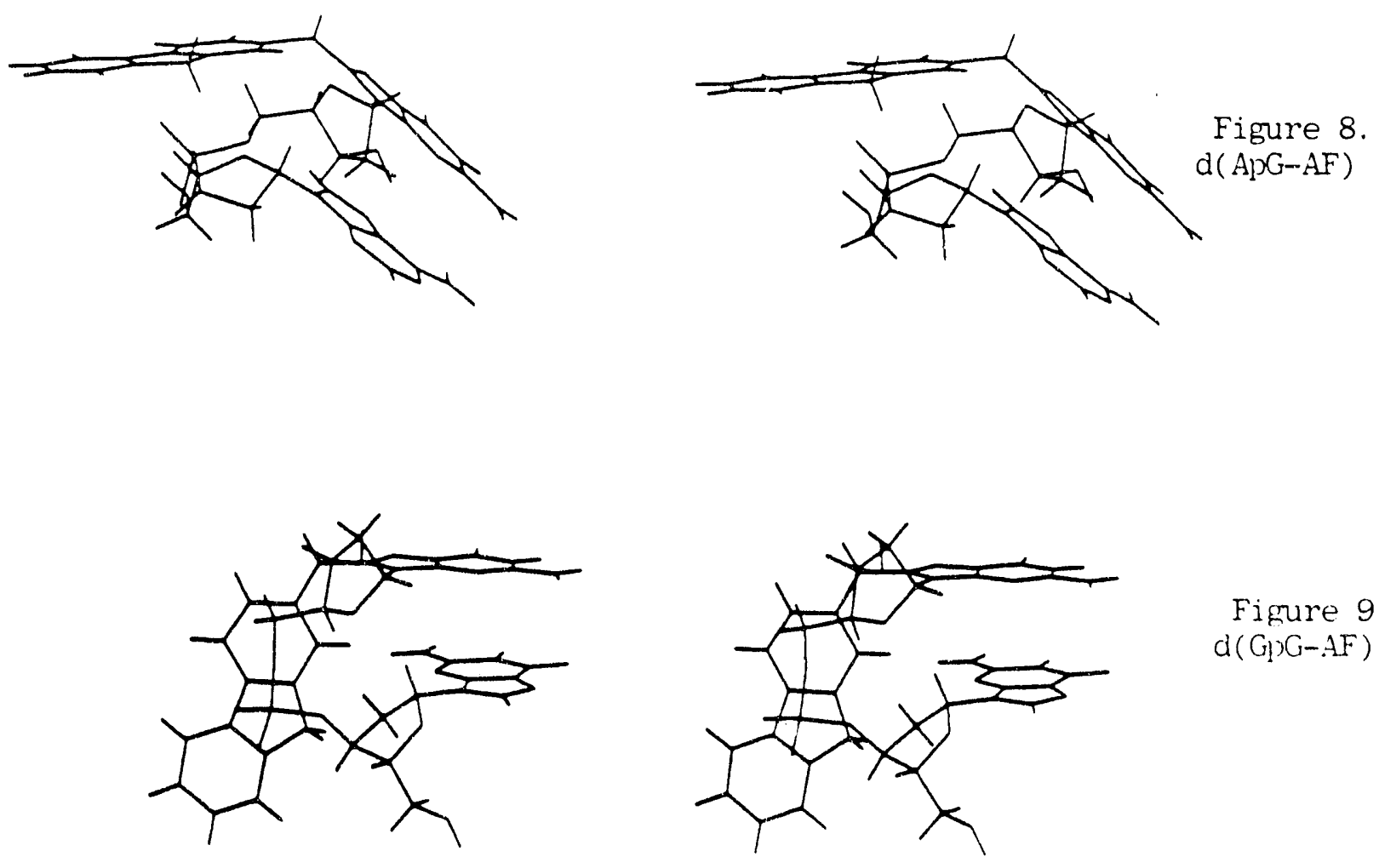

Figure 9. $d(G) G-A F)$ 
- VGLE STRANDED TRIIERS
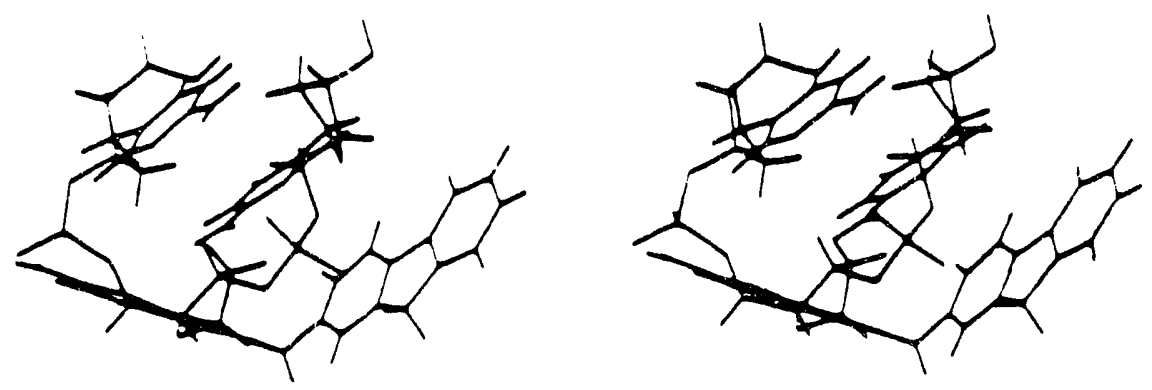

Figure 10.

$\mathrm{d}(\mathrm{CPG}-\mathrm{AF}-\mathrm{pC})$

$\Delta E=0 \mathrm{kcal} / \mathrm{mol}$
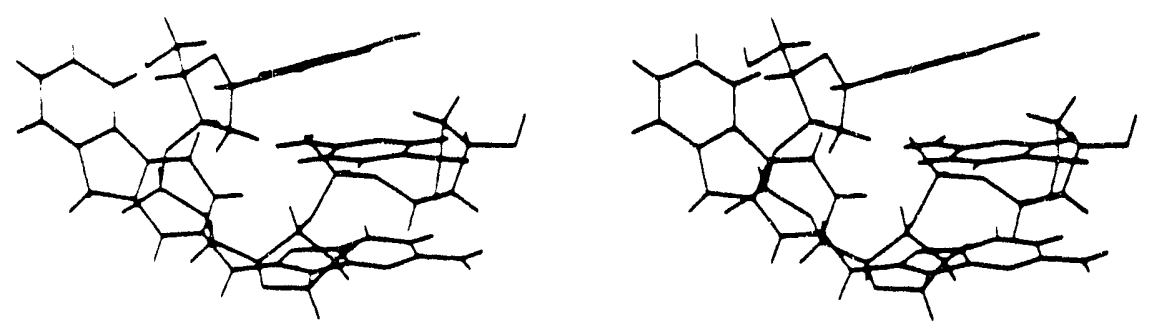

Figure 11.

$\mathrm{d}(\mathrm{CPG}-\mathrm{AF}-\mathrm{pC})$

$\Delta E=1.48 \mathrm{kcal} / \mathrm{mol}$
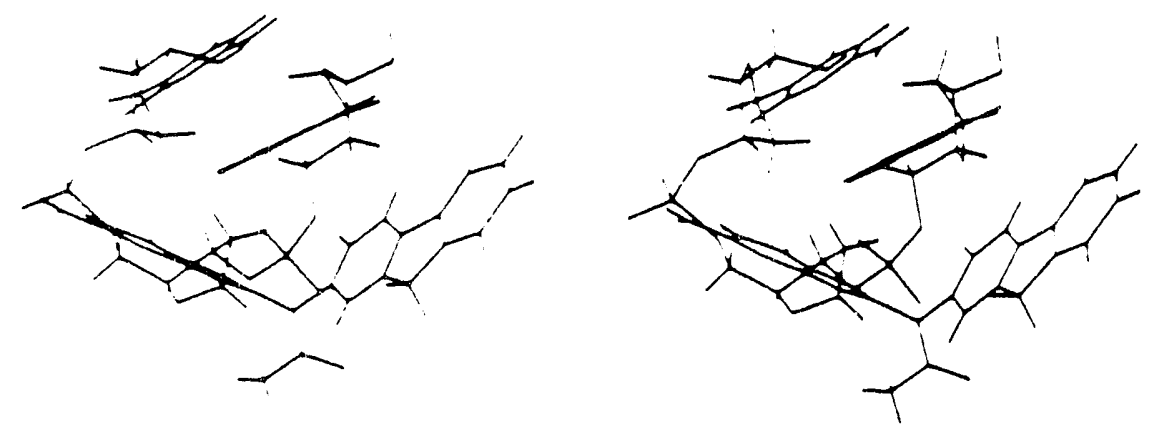

Figure 12.

$\mathrm{d}(\mathrm{CPG}-\mathrm{AHF}-\mathrm{pC})$

$\Delta E=0.05 \mathrm{kcal} / \mathrm{mol}$
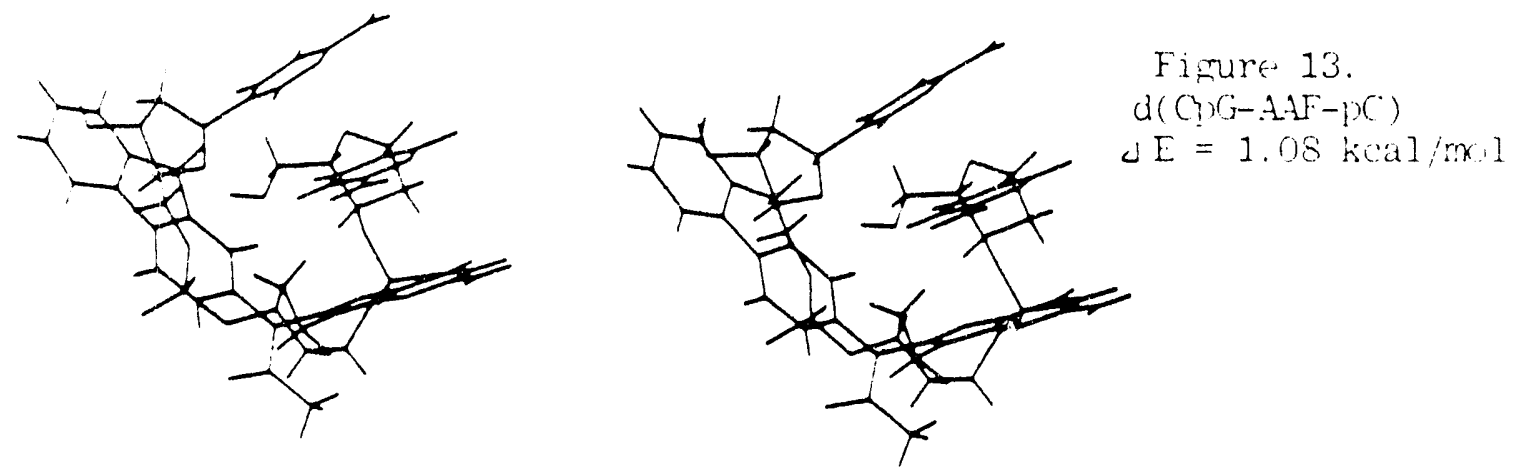

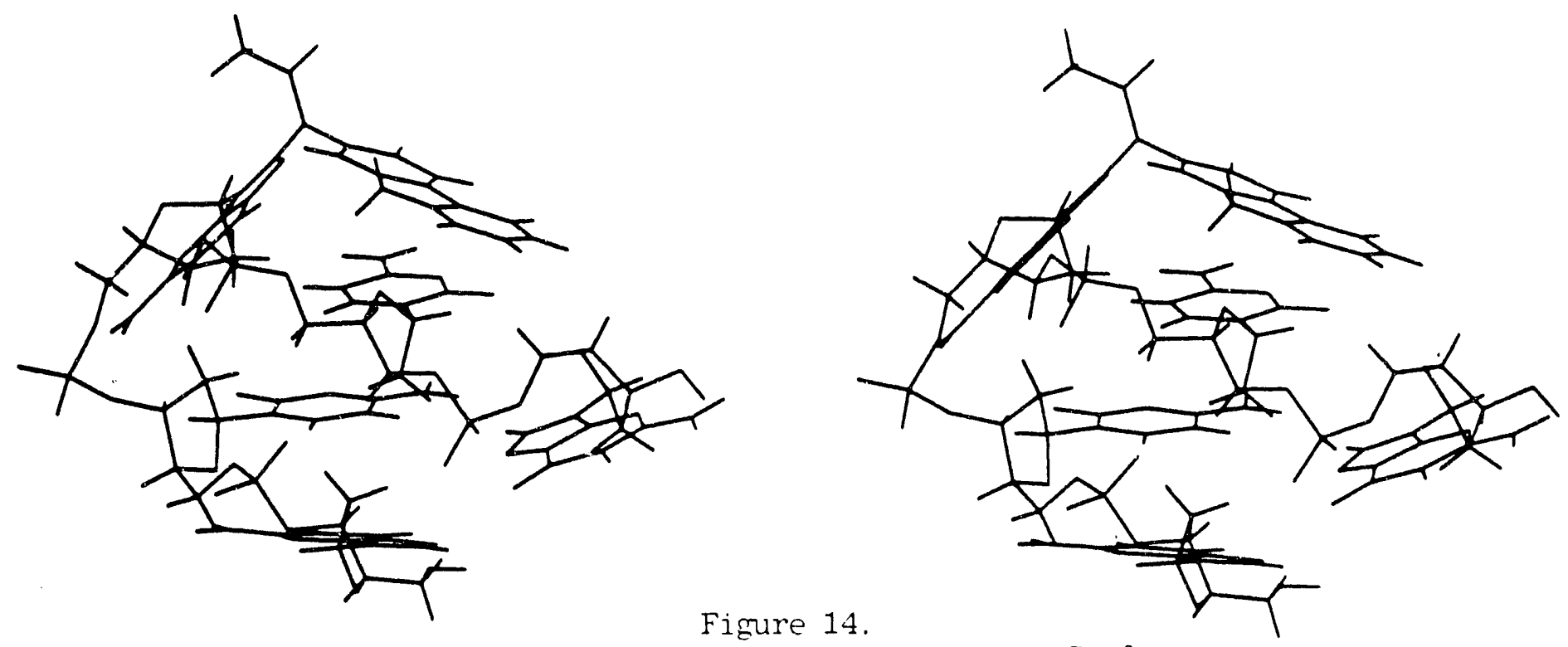

d(CPCDG-AF-DCPG Lowest Energy Conformer

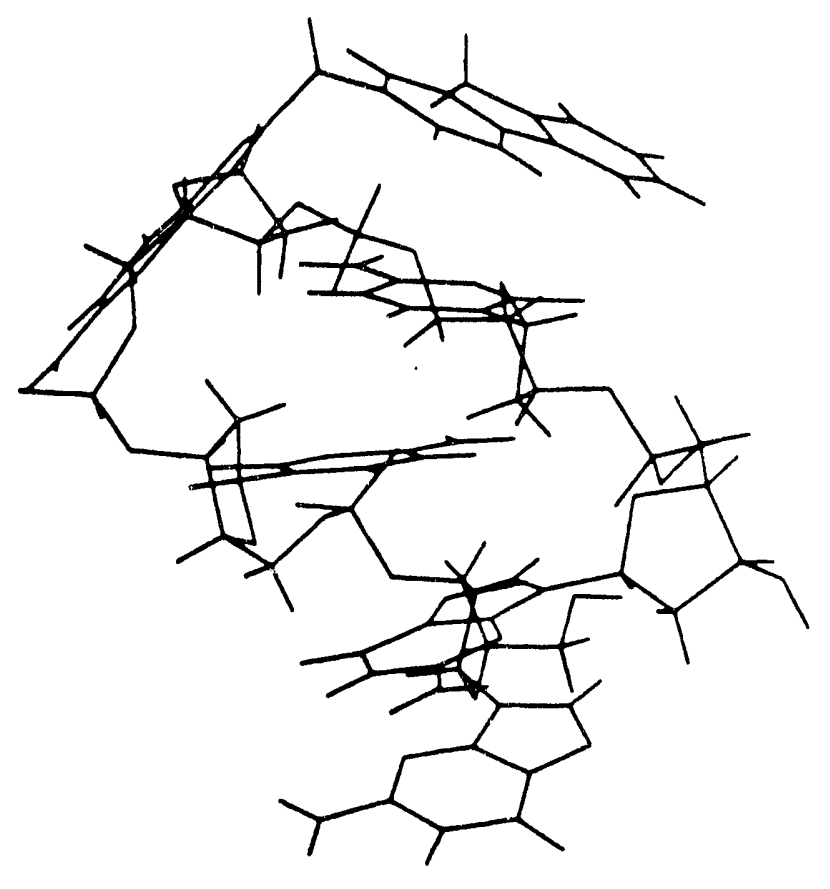

Figure 15.

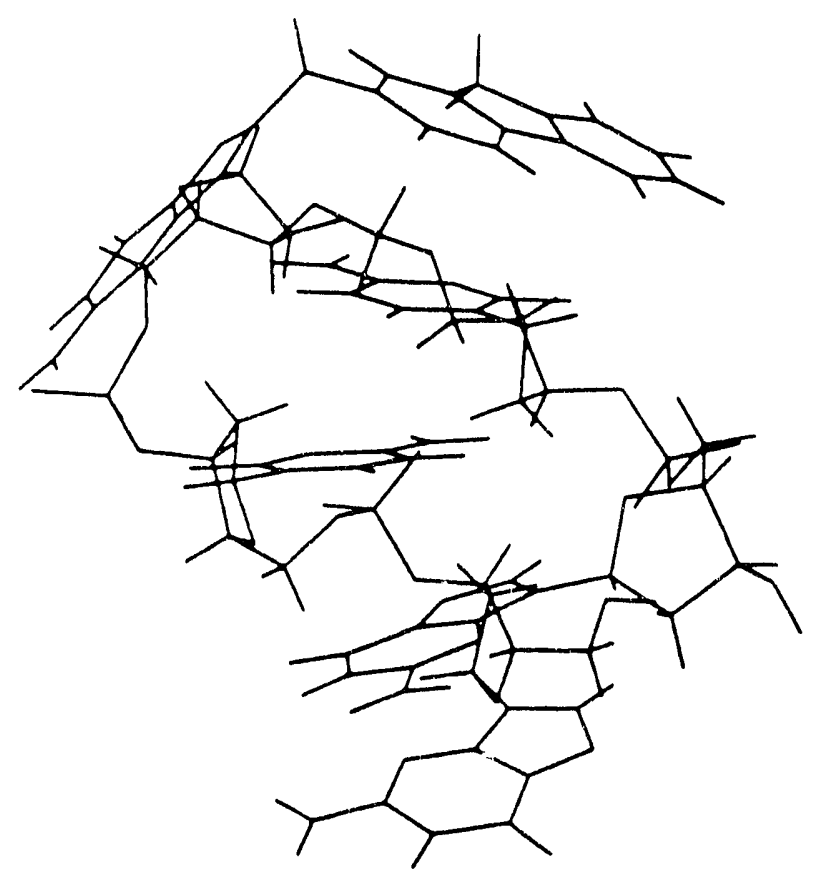

d(G)CpG-AHF-pCDG Lowert Energ? Conformer 

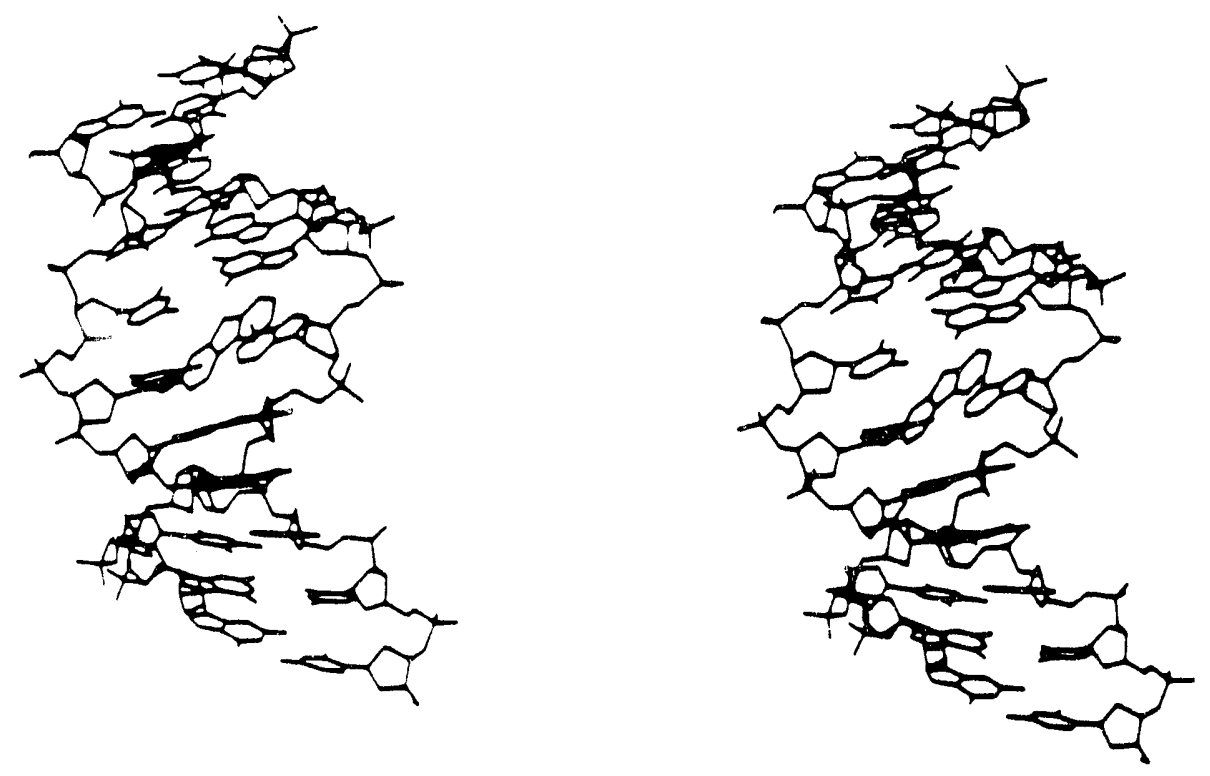

(a)
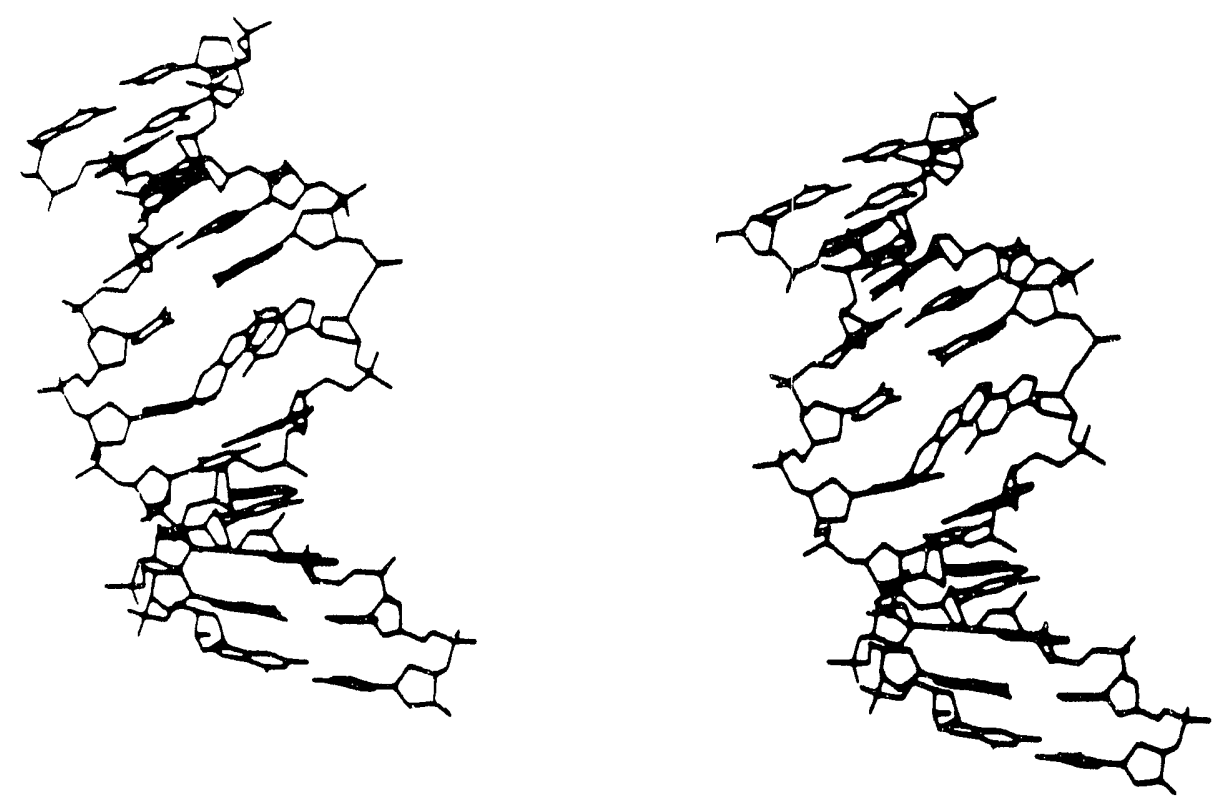

Figure 16. Structures of AF modified DNA duplex 11-nk rs computed with NDP measured interproton distances obtained from Patel-Grunberger ]aboratories (columbia liniverstr). (a) AF-G...I (b) AF-G...G 

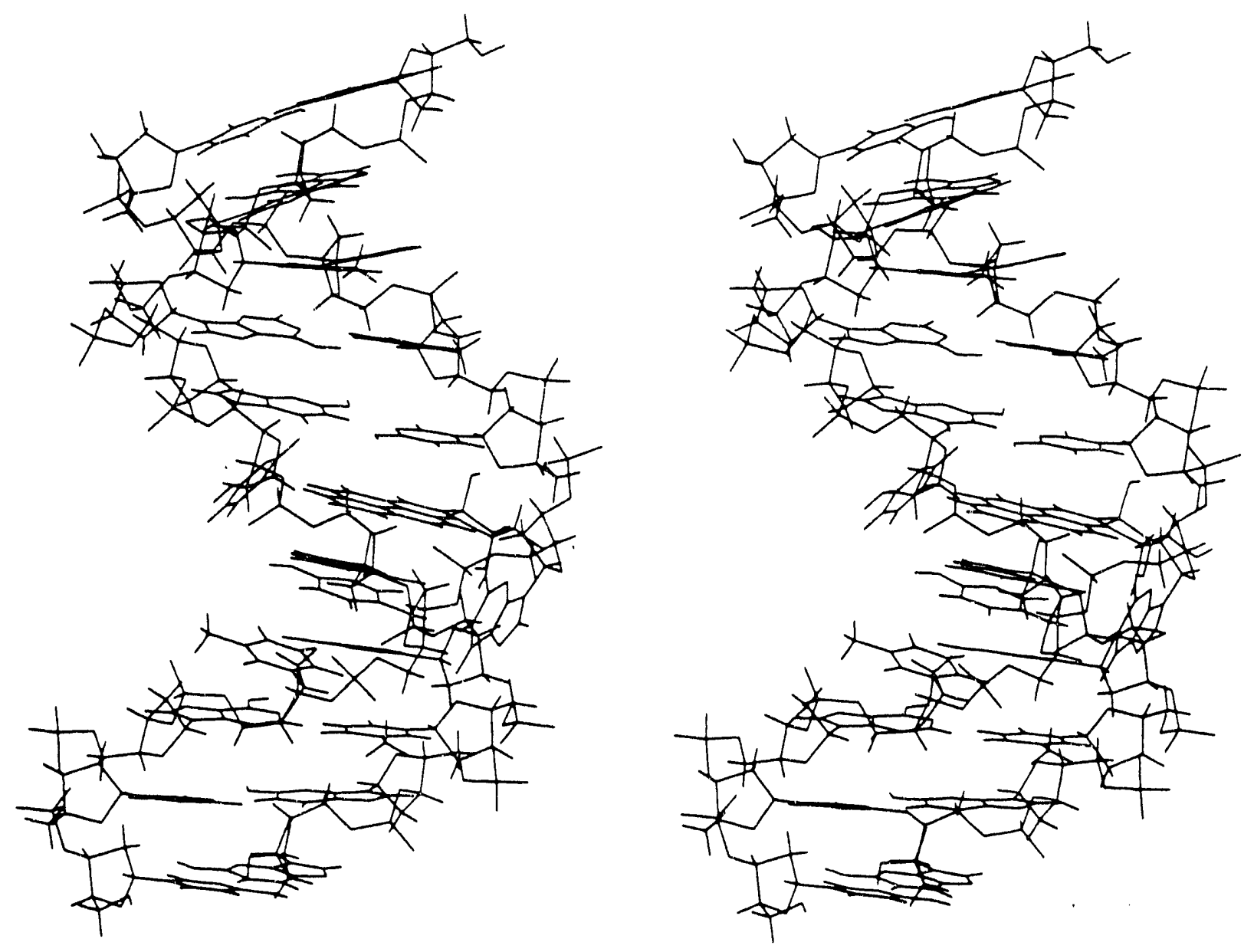

Figure 17. Structure of the (+) cis-anti adduct of BPDE in a duplex 11-mer, computed with the aid of NMR data obtained in the laboratory of D. J. Patel (Columbia). 
1. Prediction of DNA structure from sequence: A Build-up Technique". Hingerty, B. E.,Figueroa, S., Hayden, T. and Broyde, S., Biopolymers 28,1195-1222 (1989).

2. "NMR and Computational Characterization of the $\mathrm{N}$-( deoxyguanosin-8-yl) Aminofluorene Adduct ( $A F$ ) G Opposite Adenosine in DNA: ( $A F$ ) G Syn-A Anti Pair Formation and its PH Dependence". Norman, D.. Abuaf, P., Hingerty, B. E., Live, D., Grunberger, D. Broyde, S., and Patel, D. J., Biochemistry $28,7462-7476$ (1989).

3. "Unusual Hydrogen Bonding patterns in AF and AaF Modified ONA", in 4 th International Conference on $N$-substituted aryl Compounds, Broyde, S., Hingerty, B. E., Shapiro, R. and Norman, D., P. Howard, Ed., Plenum Press, NY 1990.

4. "Minor Groove Binding Models for Acetylaminofluorene Modified ONA", Shapiro, R., Hingerty, B. E. and Broyde, S., J. Biomolec. Struct. and Dynam., 7, 493-513 (1989).

5. "Search Strategies, Minimization Algorithms and Molecular Dynamics simulations for Exploring Conformational Spaces of Nucleic Acids", Schlick, T., Hingerty, B. E., Peskin, C., Overton, M. and Broyde, S., in Theoretical Biochemistry and Molecular Biophysics, $D$. Beverige and. R. Lavery, Eds., Adenine Press, Schenectady, NY 1990.

6. "NMR and computational Characterization of Mitomycin Cross Linked to Adjacent Deoxyguanosines in the Minor Groove of the d(TACGTA).d(TACGTA) DUPlex", Norman, D., Live, D.. Sastry, G., Lipman, R., Hingerty, B. E., Tomasz, M. Broyde, S. and Patel, D. J.., Biochemistry 29, 2861-2875 (1990).

7. "Atomic Resolution Structures of DNA and DNA Modified by Carcinogens", Hingerty, B. E. and Broyde, S., International Journal of Supercomputer Applications 4,11-21 (1990).

8. "Structures of the (+) and (-)-trans-7,8-0ihydroxy-anti-9,10-epoxy-

$7,8,9,10$-tetrahydrobenzo( a pyrene Adducts to Guanine-N2 in a Duplex Dodecamer", Singh, S. B., Hingerty, B. E., Singh, U. C., Greenberg, J. P., Geacintov, N. E. and Broyde, S., Cancer Research 51, 3482-3492 (1991).

9. "Predicting Structures of DNA and Carcinogen Modified DNA by Build-Up Techniques", Hingerty, $B$. E., Broyde, $S$. and Shapiro, R. in C. R. Cantor and H. A. Lim, Editors, First International Conference on Electrophoresis, Supercomputing and the Human Genome, world Scientific Publishing Co., London, PP. 96 - 100 (1991).

10. "Static and Animated Views of DNA Bound to a Tumorigenic Chemical". Broyde, S., Hingerty, B. E., Xu, R., O'Handley, S. F.., and Krugh, T. R.. Proceedings of the First Energy Research Power Supercomputer Users Symposium, May 21-22, 1991, Gajthersburg, Maryland, U. S. Dept. of Energy. Available to the public from the National Technical Information Service, U.S. Department of Commerce, 5285 Port Royal Road, Springfield, Virginia 22161. 
11. "Solution Conformation of the Major Adduct Between the Carcinogen (t)-anti- Benzoapyrene Diol Epoxide and DNA", Cosman, M., de los Santos, C., Fiala, R., Hingerty, B. E.. Singh, S. B., Ibanez, V., Margulis, L., Live, D., Geacintov, N., Broyde, S. and Patel, D. J.. Proc. Natl. ACad. SCI. USA 89, 1914-1918 (1992).

12. "Structure of an Acetylaminofluorene (AAF) Modified DNA Oligomer" O'Handley, S. F., Sanford, D. G., Xu, R., Lester, C.. Hingerty, B. E., Broyde, S. and Krugh, T. R., in structure and Function, volume I, Nucleic Acids, 1992, po. 137-146. Adenine Press, Schenectady. NY.

13. Influence of Chirality of Anti-Benzo-a-pyrene-diol-Epoxide on Solution Conformations of its DNA Covalent Adducts: The (-)-trans-antiBPG.C Adduct Structure and Comparison with the (+)-trans-anti Enantiomer. Biochemistry 31, 5245-5252 (1992). 

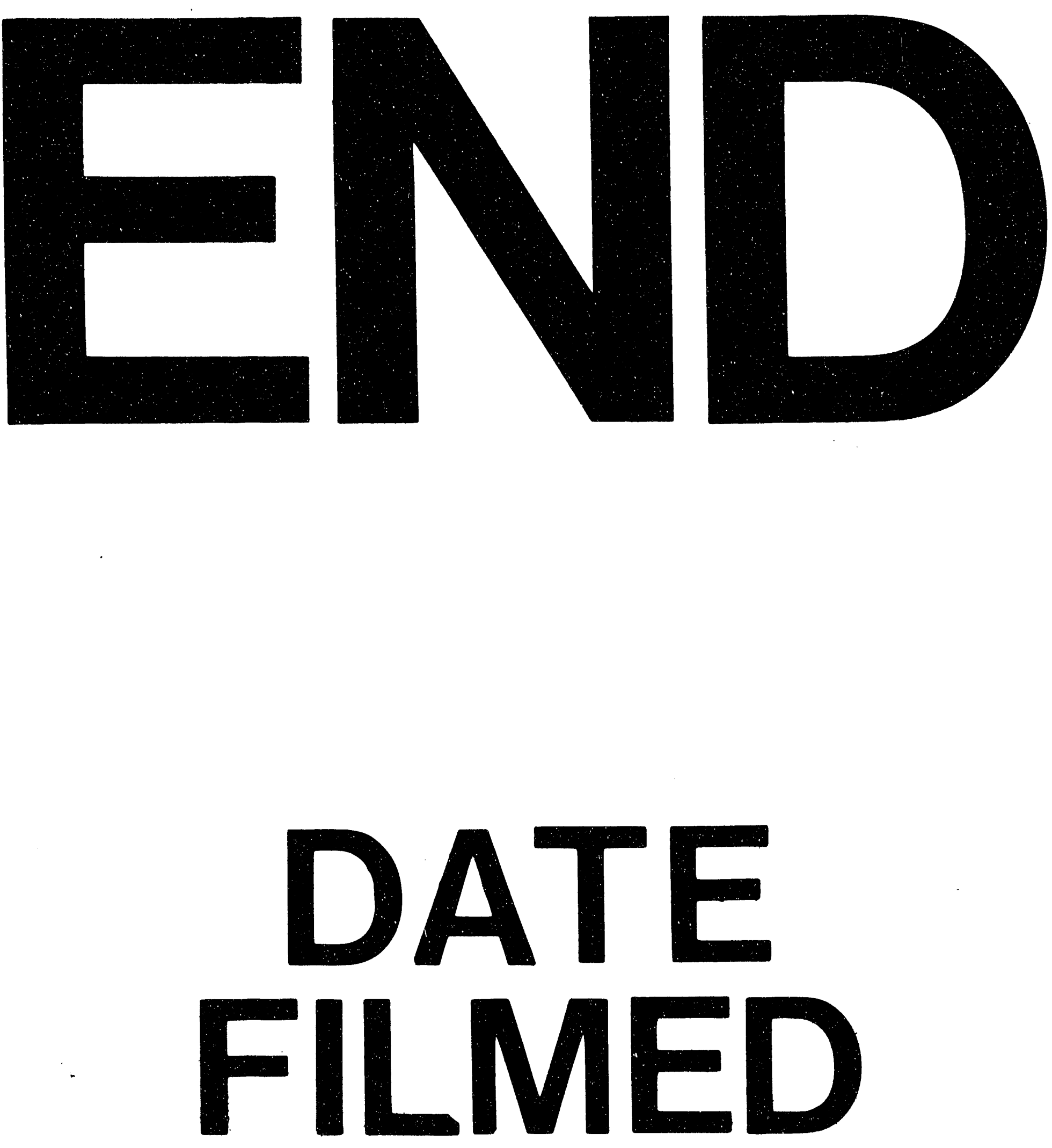

I

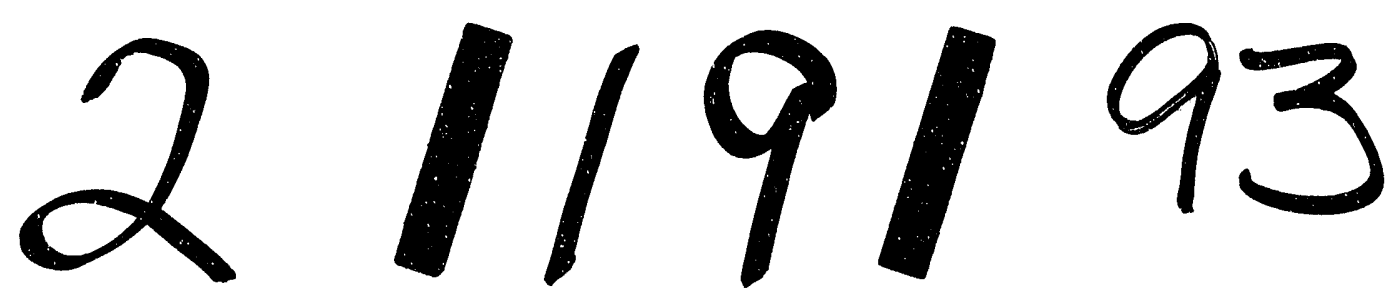


